\title{
Floristic study of Jeonggwangsan Mt. (Yongin, Korea)
}

\section{Ji-Hyeon JEON, Myong-Suk CHO, Hee-Young GIL ${ }^{1}$, Seon-Hee KIM, Petra JUNES, Hee-Seung SEO and Seung-Chul KIM*}

\author{
Department of Biological Sciences, Sungkyunkwan University, Suwon 16419, Korea \\ ${ }^{1}$ Korea National Arboretum, Division of Forest Biodiversity, Pocheon 11186, Korea \\ (Received 10 November 2018; Revised 2 January 2019; Accepted 23 March 2019)
}

\begin{abstract}
In this study, we investigated the flora of Jeonggwangsan Mt. (Yongin, Korea) from May of 2015 to September of 2016. Through 14 independent field investigations, we identified a total of 367 taxa of vascular plants, including 89 families, 234 genera, 323 species, six subspecies, 34 varieties, and four formae. Eight taxa were endemic to Korea, while 27 were naturalized in Korea. Nineteen taxa were the floristic regional indicator plants in Korea: four in Rank VI, four in Rank III, two in Rank II, and nine in Rank I. A total of 59 taxa were designated as controlled Korean biological resources, requiring special permission for export to outside countries. Two taxa were listed on the Red List of Korea, including one Near Threatened (NT) taxon (Hololeion maximowiczii Kitam.) and one Least Concern (LC) taxon (Iris minutoaurea Makino).
\end{abstract}

Keywords: Jeonggwangsan Mt., flora, endemic plants, floristic regional indicator plants, naturalized plants

정광산 $(562.1 \mathrm{~m})$ 은 행정구역상 경기도 용인시 처인구 모현면에 속하며, 북위 $37^{\circ} 19^{\prime}$, 동경 $127^{\circ} 16^{\prime}$ 로 용인시 모현 면과 광주시 도척면의 경계에 위치한다. 이 경계를 따라 정광산의 북쪽으로는 노고봉 $(573.6 \mathrm{~m})$ 이 바로 위치하며 다시 백마산 $(460.6 \mathrm{~m})$ 으로 이어지고, 남쪽으로는 태화산 (641.1 m)과 정수산 $(395.9 \mathrm{~m})$ 이 이어진다. 본 조사 구역인 용인시 일대는 중부 아구에 속하며, 중부 서안형 기후에 속하기 때문에 북부 지역 식물상과 남부 지역 식물상이 혼재되어 나타나는 전형적인 중부 지방 식물상으로, 신갈 나무(Quercus mongolica Fisch. ex Ledeb.), 상수리나무 (Quercus acutissima Carruth.), 소나무(Pinus densiflora Siebold \& Zucc.) 등이 주된 식생을 이루는 온대 혼효림을 이룬다(Kim, 2009). 지질학적으로 정광산이 위치하고 있 는 모현면은 대부분이 호상편마암으로 이루어져 있고, 일 부는 화강암질 편마암으로 되어있다(Kwon, 2009).

정광산은 서사면과 동사면의 크고 작은 계곡을 따라 물 이 흐르며, 각각 용인 경안천과 광주 노곡천으로 흘러 든 다. 이 중 서사면의 용인시 모현면 초부리를 향해 물이 흐 르는 계곡을 따라 용인자연휴양림이 조성되어있어, 캠핑 장 및 숙박시설과 함께 에코어드벤쳐 등의 놀이 시설이 개발되어 있고 정상부에는 패러글라이딩 활공장이 설치
되어 있다. 이에 서사면을 따라서는 여러 시설물뿐만 아 니라 등산로 및 시설물 접근을 위한 임도가 개발되어 있 으며, 이로 인해 사람들의 접근 역시 용이하여 많은 등산 객과 휴양객들이 많이 찾아와 일부 식생이 파괴되어 조림 되어 있다. 동사면인 광주시 도척면 상림리로도 일부 산 림이 일본잎갈나무(Larix kaempferi (Lamb.) Carrière) 및 잣 나무(Pinus koraiensis Siebold \& Zucc.)로 조림되어 있다.

본 조사지역과 남쪽으로 인접하고 있는 태화산의 식물 상은 Choi et al. (2001)의 연구에 의해 56과 103속 132분류 군이 보고된 바 있으며, Ko and Shin (2009)에 의해 50과 94 속 116 종 11 변종 7 품종의 총 130 분류군이 보고된 바 있다. 하지만 정광산의 식물상에 대한 연구는 현재까지 직접 이 루어진 바 없으며 본 연구 조사로 처음 이루어졌다. 정광 산은 용인자연휴양림과 주변 민가를 포함하여 많은 개발 이 진행되고 있으며 사람들의 접근이 쉬워 식물상이 계속 해서 파괴되기 쉽지만 용인자연휴양림을 활용한 정광산 의 생물자원보전 가능성이 기대되는 만큼 정광산을 중심 으로 한 자세한 식물상 조사가 요구되었다. 따라서 본 연 구에서는 정광산의 식물상을 조사하고 이에 분포하는 주 요식물을 확인함으로써, 이를 식물 자원 보존을 위한 기 초자료로 활용하고자 한다.

*Author for correspondence: sonchus96@skku.edu 
Table 1. The dates and routes of floral investigation in Jeonggwangsan Mt.

\begin{tabular}{cl}
\hline \hline Date & \multicolumn{1}{c}{ Investigation routes } \\
\hline 8 May 2015 & Bamtigol $\rightarrow$ Jeonggaengigol $\rightarrow$ Seongjaegol \\
5 Jun 2015 & Eco-Adventure (Yongin Natural Recreation Forest) $\rightarrow$ Jeonggaengigol \\
9 Jul 2015 & Jilma Gogae $\rightarrow$ Jeonggaengi $\rightarrow$ Keungol $\rightarrow$ Jeonggwangsan Mt. $\rightarrow$ Nogobong \\
27 Aug 2015 & Jeonggaengi $\rightarrow$ Keungol \\
5 Oct 2015 & Bamtigol $\rightarrow$ Gipeungol $\rightarrow$ Barinamugol $\rightarrow$ Baramnaemi Gogae \\
22 Oct 2015 & Gipeungol $\rightarrow$ Eco-Adventure \\
7 Apr 2016 & Gamagol $\rightarrow$ Bamtigol \\
20 Apr 2016 & Gipeungol $\rightarrow$ Eco-Adventure $\rightarrow$ Bamtigol \\
17 May 2016 & Seungbangteo $\rightarrow$ Jeonggaengi $\rightarrow$ Keungol \\
2 Jun 2016 & Jilma Gogae $\rightarrow$ Jeonggaengi $\rightarrow$ Keungol \\
22 Jun 2016 & Neungangol $\rightarrow$ Seongjaegol \\
15 Jul 2016 & Gipeungol $\rightarrow$ Jeonggaengigol $\rightarrow$ Jeonggwangsan Mt. \\
2 Sep 2016 & Seongjaegol $\rightarrow$ Jeonggaengigol $\rightarrow$ Jeonggwangsan Mt. \\
28 Sep 2016 & Gipeungol $\rightarrow$ Barinamugol \\
\hline
\end{tabular}
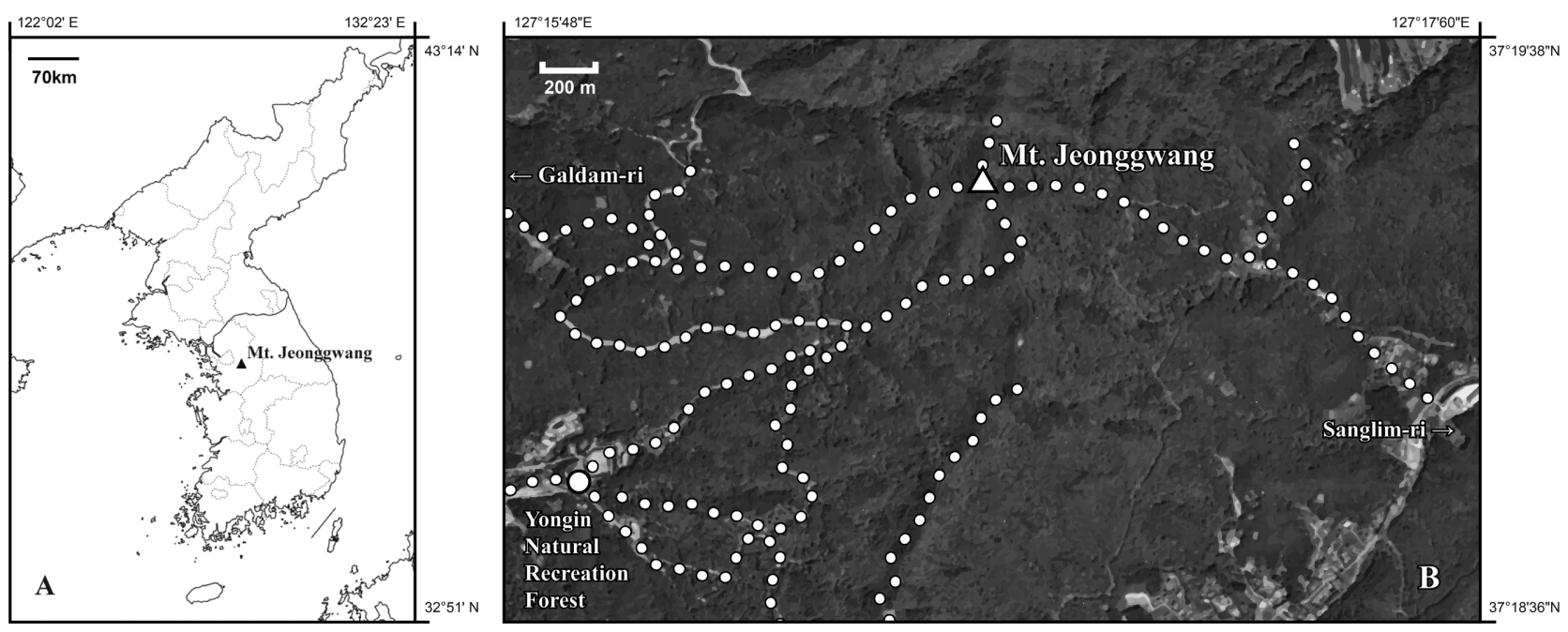

Fig. 1. The map of Jeonggwangsan Mountain. (A) The location of Jeonggwangsan Mt. in the Korean Peninsula. (B) The investigation routes in this study.

\section{재료 및 방법}

정광산의 관속식물상을 파악하기 위해 용인자연휴양 림 일대와 광주시 도척면 상림리 일대를 중심으로 하여 2015년 5월부터 2016년 9월까지 총 14회에 걸쳐 현지조 사가 수행되었다(Fig. 1, Table 1). 조사재료는 동정의 정확 도를 높이기 위해 꽃이나 열매 등 생식기관이 있는 개체 를 중심으로 채집하였다. 채집된 재료는 Lee (2003), Lee (2006), Oh (2006), Flora of Korea Editorial Committee (2007), Chang et al. (2011), Park et al. (2011), Lee and Lee
(2015) 등의 도감을 이용하여 동정하였으며, 학명 및 분류 체계는 국가생물종목록(National List of Species of Korea; National Institute of Biological Resources, 2018)을 우선적 으로 따랐으나 일부 국가표준식물목록(A Synonymic List of Vascular Plants in Korea; Korea National Arboretum and The Korean Society of Plant Taxonomists, 2007)을 참조하 였다. 주요식물의 검토에 있어서 특산식물은 Chung et al. (2017)의 연구를, 귀화식물은 국가표준식물목록(A Synonymic List of Vascular Plants in Korea; Korea National Arboretum and The Korean Society of Plant Taxonomists, 
2007)을 참조하였다. 식물구계학적 특정식물은 제4차 전 국자연환경조사 지침(Ministry of Environment and National Institute of Environmental Research, 2014)을, 국외 반출 승인대상 식물자원은 National Institute of Biological Resources (2016)의 연구를 참조하였다. 멸종위기종 및 적 색목록은 한국의 멸종위기 야생동·식물 적색자료집 $(\mathrm{Red}$ Data Book of Endangered Vascular Plants in Korea; National Institute of Biological Resources, 2012)과 Korean Red List of Threatened Species (National Institute of Biological Resources, 2014)를 참조하였다. 조사에서 채집된 재료들 은 모두 건조표본으로 제작하여, 국립생물자원관 (National Institute of Biological Resources)에 확증표본으로 보관하였다.

\section{결과 및 고찰}

이번 조사를 통해 정광산에서 89과 234속 323종 6아종 34 변종 4품종 총 367 분류군이 확인되었다(Table 2, Appendix 1). 이는 국가표준식물목록에 의거한 한반도 자 생 및 귀화 관속식물 4,500 분류군의 $8.2 \%$ 에 해당하며, 이 중 양치식물은 4 과 5 속 7 종의 7 분류군, 나자식물은 1 과 2 속 2종의 2 분류군, 피자식물은 84 과 227속 314 종 6 아종 34 변종 4품종의 358 분류군이 확인되었으며, 피자식물 358 분류군 중에서 쌍자엽식물이 73 과 186속 249종 6 아종 30 변종 3품종의 288 분류군을, 단자엽식물이 11 과 41 속 65 종 4 변종 1품종의 70 분류군을 차지하였다(Table 2).

\section{특산식물}

정광산에서 확인된 378 분류군 중 한국에만 분포하는 것 으로 알려진 특산식물은 Lycoris flavescens M. Y. Kim \& S. T. Lee (붉노랑상사화), Aster koraiensis Nakai (벌개미취), Weigela subsessilis (Nakai) L. H. Bailey (병꽃나무), Scutellaria insignis Nakai (광릉골무꽃), Aconitum pseudolaeve Nakai (진범), Salix koriyanagi Kimura ex Goerz (키버들), Paulownia coreana Uyeki (오동나무), Hemerocallis hakuunensis Nakai (백운산원추리)로 총 8과 8속의 8분류군 이 확인되었다(Table 3). 이는 Chung et al. (2017)의 연구에 서 보고한 특산식물 360 분류군의 약 $2.2 \%$ 를 차지한다.

\section{식물구계학적 특정식물}

식물구계학적 특정식물은 한반도의 구계분석을 통해 각각의 분포범위에 따라 $\mathrm{I}-\mathrm{V}$ 의 5 개의 등급으로 구분된 식 물 분류군을 의미하며, $\mathrm{V}$ 등급으로 갈수록 제한된 구역에 분포하며 I등급으로 갈수록 더 넓은 구계에 걸쳐 분포함 을 나타낸다. 이러한 식물구계학적 특정식물은 식물의 특 성을 이해하고 식물과 서식처의 보존에 우선순위를 정하 는 데에 중요하게 사용될 수 있다(Choi, 2016). 정광산에서 확인된 식물구계학적 특정식물은 총 14 과 19 속의 19 분류 군이 확인되었다(Table 4). 한 아구에만 분포하는 IV등급 분류군은 Festuca rubra L. (왕김의털), Poa viridula Palib. (청 포아풀), Lycoris flavescens M. Y. Kim \& S. T. Lee (붉노랑상 사화)와 Prunus davidiana (Carrière) Franch. (산복사)의 4분 류군, 두 아구에 분포하는 III등급 분류군은 Spiraea

Table 2. The categorized taxon number of vascular plants in Jeonggwangsan Mt.

\begin{tabular}{lccccccc}
\hline \hline & Taxa & Family & Genus & Species & Subspecies & Variety & Forma \\
\hline Pteridophytes & & 4 & 5 & 7 & - & - & - \\
Gymnosperms & & 1 & 2 & 2 & - & - & - \\
Angiosperms & Monocots & 11 & 41 & 65 & - & 4 & 1 \\
& Dicots & 73 & 186 & 249 & 6 & 30 & 3 \\
& Subtotal & 84 & 227 & 314 & 6 & 34 & 4 \\
\hline
\end{tabular}

Table 3. The list of the endemic plants to Korea in Jeonggwangsan Mt.

\begin{tabular}{ll}
\hline \hline \multicolumn{1}{c}{ Family } & \multicolumn{1}{c}{ Scientific name } \\
\hline Ranunculaceae & Aconitum pseudolaeve Nakai 진범 \\
Salicaceae & Salix koriyanagi Kimura ex Goerz 키버들 \\
Lamiaceae & Scutellaria insignis Nakai 광릉골무꽃 \\
Scrophulariaceae & Paulownia coreana Uyeki 오동나무 \\
Diervillaceae & Weigela subsessilis (Nakai) L. H. Bailey 병 꽃나무 \\
Asteraceae & Aster koraiensis Nakai 벌개미취 (Cultivated) \\
Liliaceae & Hemerocallis hakuunensis Nakai 백 운산원추리 \\
Amaryllidaceae & Lycoris flavescens M. Y. Kim \& S. T. Lee 붉노랑상사화 (Cultivated) \\
\hline
\end{tabular}


Table 4. The list of floristic regional indicator plants of Korea in Jeonggwangsan Mt.

\begin{tabular}{|c|c|c|}
\hline Category & Family & Scientific name \\
\hline \multirow[t]{4}{*}{ IV } & Rosaceae & Prunus davidiana (Carrière) Franch. 산복사 (Cultivated) \\
\hline & Poaceae & Festuca rubra L. 왕김의털 \\
\hline & & Poa viridula Palib. 청포아풀 \\
\hline & Amaryllidaceae & $\begin{array}{l}\text { Lycoris flavescens M. Y. Kim \& S. T. Lee 붉노랑상사화 } \\
\text { (Cultivated) }\end{array}$ \\
\hline \multirow[t]{4}{*}{ III } & Rosaceae & Spiraea salicifolia L. 꼬리조팝나무 \\
\hline & Lamiaceae & Scutellaria insignis Nakai 광릉골무꽃 \\
\hline & Rubiaceae & Asperula odorata L. 선갈퀴 \\
\hline & Poaceae & Diarrhena fauriei (Hack.) Ohwi 광릉용수염풀 \\
\hline \multirow[t]{2}{*}{ II } & Primulaceae & Primula sieboldii E. Morren 앵초 \\
\hline & Iridaceae & Iris minutoaurea Makino 금붓꽃 \\
\hline \multirow[t]{9}{*}{ I } & Dryopteridaceae & Dryopteris uniformis (Makino) Makino 곰비늘고사리 \\
\hline & Pinaceae & Pinus koraiensis Siebold \& Zucc. 잣나무 \\
\hline & Ranunculaceae & Aconitum jaluense Kom. 투구꽃 \\
\hline & & Clematis patens C. Morren \& Decne. 큰꽃으아리 \\
\hline & Saxifragaceae & Chrysosplenium japonicum (Maxim.) Makino 산괭이눈 \\
\hline & Rosaceae & Malus baccata (L.) Borkh. 야광나무 \\
\hline & Oxalidaceae & Oxalis obtriangulata Maxim. 큰갱이밥 \\
\hline & Balsaminaceae & Impatiens nolitangere L. 노랑물봉선 \\
\hline & Asteraceae & Cirsium pendulum Fisch. ex DC. 큰엉겅퀴 \\
\hline
\end{tabular}

salicifolia L. (고리조팝나무) 등 4분류군, 백두대간을 중심 으로 분포하는 II등급 분류군은 Iris minutoaurea Makino ( 금붓꽃)와 Primula sieboldii E. Morren (앵초)의 2분류군, 그 리고 세 아구에 분포하는 I등급 분류군은 Malus baccata (L.) Borkh. (야광나무), Oxalis obtriangulata Maxim. (큰괭이 밥) 등 9 분류군이 확인되었다. IV등급에 속하는 붉노랑상 사화와 산복사는 정갱이에서 큰골로 올라가는 계곡 그늘 진 곳에서 발견되었으며, 산지임에도 불구하고 분포지역 까지 임도가 이어지고 주택과 농지가 있어 인위적으로 도 입되었을 가능성이 있는 것으로 본다. 따라서 이들 분류 군의 경우 추가적인 조사를 통해 정광산에서의 분포 현황 과 실체를 파악할 필요가 있으며, 종의 자생이 확인될 경 우 추가적인 개발이나 사람들의 접근으로부터 자생지를 보호할 필요가 있다.

\section{국외반출 승인대상 생물자원}

국외반출 승인대상 생물자원은 생물다양성협약에 근 거해 자생생물 자원을 확보하고 관리하여 국가 생물주권 을 강화하고자 국외로의 무단방출이 제한된 고유종 및 경 제적으로 활용가치가 있는 자생생물 자원이다(National Institute of Biological Resources, 2016). 이번 조사로 정광산 에서 국외반출 승인대상 생물자원은 특산식물 8분류군을
포함하여 총 34 과 53속의 59분류군이 확인되었다 (Appendix 1). 이는 National Institute of Biological Resources (2016)의 연구에서 선정된 국외반출 승인대상 생물자원 중 관속식물 1,077 분류군 중 약 $5.5 \%$ 를 차지한다.

\section{멸종위기식물 및 적색목록식물}

적색목록식물은 국내에 자생하는 관속식물 중 International Union for Conservation of Nature (IUCN)에서 정한 적색목록 범주와 기준에 해당하는 분류군을 정리한 것으로, 이 중 위급(Critically Endangered, $\mathrm{CR}$ ), 위기 (Endangered, $\mathrm{EN})$, 취약(Vulnerable, $\mathrm{VU})$ 을 중심으로 야생 에서 절멸 위기에 처한 분류군을 환경부에서 멸종위기식 물로 선정하였다(National Institute of Biological Resources, 2012). 이번 조사로 정광산에서 멸종위기식물은 확인되지 않았으나 총 2 과 2 속의 2 분류군의 적색목록식물이 확인 되었다(Table 5). 이는 전체 적색목록식물 543분류군 중 약 $3.7 \%$ 를 차지한다(National Institute of Biological Resources, 2012). 이 중 Hololeion maximowiczii Kitam. (께묵)가 현재는 위급, 위기, 취약에 해당하지 않으나 가까운 미래에 멸종 위기 범주에 포함될 수 있는 준위협(Near Threatened, NT) 에 해당하였으며, Iris minutoaurea Makino (금붓꽃)가 적색 목록 기준에는 포함되나 개체수와 집단이 많아 특정 범주 
에는 포함되지않는 관심대상(Least Concern, LC)에 해당되 었다. 이번 조사에서 준위협에 해당하는 께묵은 용인자연 휴양림 내 깊은골에서 에코어드벤쳐로 이어지는 숲길에 서 발견되었다. 개체수가 적지는 않았으나 산자락의 숲 속임에도 불구하고 가까이까지 임도가 존재하고 휴양객 을 대상으로 한 산책길이 자생지를 통하므로 관심을 가지 고 자생지를 보호할 필요가 있다.

\section{귀화식물}

이번 조사를 통해 정광산에서는 Erigeron annuus (L.) Pers. (개망초), Ambrosia artemisiifolia L. (돼지풀), Erechtites hieracifolia (L.) Raf. ex DC. (붉은서나물) 등을 포함하여 총 12 과 27 속의 27 분류군의 귀화식물이 확인되 었다(Table 6). 이는 표준식물목록에 등재된 귀화식물 321 분류군의 약 $8.4 \%$ 를 차지한다(Korea National Arboretum

Table 5. The list of plants on the red list of Korea in Jeonggwangsan Mt.

\begin{tabular}{ccl}
\hline \hline Category & Family & \multicolumn{1}{c}{ Scientific name } \\
\hline NT & Asteraceae & Hololeion maximowiczii Kitam. 께묵 \\
LC & Iridaceae & Iris minutoaurea Makino 금붓꽃 \\
\hline
\end{tabular}

NT, Near Threatened; LC, Least Concern.

Table 6. The list of naturalized plants to Korea in Jeonggwangsan Mt.

\begin{tabular}{|c|c|}
\hline Family & Scientific name \\
\hline Phytolaccaceae & Phytolacca americana L. 미국자리공 \\
\hline Chenopodiaceae & Chenopodium ficifolium $\mathrm{Sm}$. 좀명아주 \\
\hline Amaranthaceae & Amaranthus retroflexus L. 털비름 \\
\hline Caryophyllaceae & Silene armeria L. 끈끈이 대나물 \\
\hline Polygonaceae & Rumex crispus L. 소리쟁이 \\
\hline Rosaceae & Potentilla supina L. 개소시랑개비 \\
\hline \multirow[t]{3}{*}{ Fabaceae } & Amorpha fruticosa L. 족제비싸리 \\
\hline & Robinia pseudoacacia L. 아까시나무 \\
\hline & Trifolium repens L. 토끼풀 \\
\hline Onagraceae & Oenothera odorata Jacq. 달맞이꽃 \\
\hline Convolvulaceae & Cuscuta pentagona Engelm. 미국실새삼 \\
\hline Scrophulariaceae & Veronica arvensis L. 선개불알풀 \\
\hline \multirow[t]{11}{*}{ Asteraceae } & Ambrosia artemisiifolia L. 돼지풀 \\
\hline & Aster pilosus Willd. 미국쑥부쟁이 \\
\hline & Bidens frondosa L. 미국가막사리 \\
\hline & Carduus crispus L. 지느러미엉겅퀴 \\
\hline & Conyza canadensis (L.) Cronquist 망초 \\
\hline & Erechtites hieracifolia (L.) Raf. ex DC. 붉은서나물 \\
\hline & Erigeron annuus (L.) Pers. 개망초 \\
\hline & Eupatorium rugosum Houtt. 서양등골나물 \\
\hline & Galinsoga quadriradiata Ruiz \& Pav. 털별꽃아재비 \\
\hline & Sonchus asper (L.) Hill 큰방가지똥 \\
\hline & Xanthium canadense Mill. 큰도꼬마리 \\
\hline \multirow[t]{4}{*}{ Poaceae } & Dactylis glomerata L. 오리새 \\
\hline & Eragrostis curvula (Schrad.) Nees 능수참새그령 \\
\hline & Festuca arundinacea Schreb. 큰김의털 \\
\hline & Lolium multiflorum Lam. 쥐보리 \\
\hline
\end{tabular}


and The Korean Society of Plant Taxonomists, 2007). 이번 조사에서는 다른 주요식물에 비해 귀화식물이 더 많은 비중으로 확인되었는데, 이는 정광산을 주변으로 민가와 농지가 많이 개발되어 있을 뿐만 아니라 이들이 도심지 로 바로 이어지기 때문에 귀화식물의 유입이 쉽기 때문 으로 보인다. 또한 용인자연휴양림을 찾는 휴양객을 통 해서도 다양한 귀화식물의 유입이 이루어졌을 것으로 생 각된다. 도심지와 가까운 곳인 만큼 이와 같은 현상이 계 속해서 이루어 질 것으로 예상되기에 지속적인 관리와 조사를 통해 귀화식물의 유입 및 분포현황을 파악할 필 요가 있다.

\section{식물상 및 식생}

본 조사지역인 정광산은 한반도 식물구계 중 중부아구 에 속하며, 신갈나무 등의 참나무류가 우점하고 당단풍 나무(Acer pseudosieboldianum (Pax) Kom.), 물푸레나무 (Fraxinus rhynchophylla Hance), 개옻나무(Toxicodendron trichocarpum (Miq.) Kuntze), 쪽동백나무(Styrax obassia Siebold \& Zucc.), 산초나무(Zanthoxylum schinifolium Siebold \& Zucc.) 등이 주로 혼재되어 있는 전형적인 온대 중부형 식물상을 보여주었다. 특히 이 지역은 경기도 서 남부로 중부 서안형 기후대에 속하여 강원도와 비슷한 기후대와 식물상을 보이는 경기 동북부 산지와는 구분 되었다(Choi et al., 2001; Kim, 2009).

이번 조사 결과 초부리 방면 에서는 소나무, 잣나무 등 의 상록수종과 함께 신갈나무, 갈참나무(Quercus aliena Blume) 등의 참나무류, 층층나무(Cornus controversa Hemsl.), 고로쇠나무(Acer pictum var. mono (Maxim.) Franch.), 당단풍나무, 잔털벚나무(Prunus serrulata var. pubescens (Makino) Nakai), 산초나무, 생강나무(Lindera obtusiloba Blume), 누리장나무(Clerodendrum trichotomum Thunb.), 난티잎개암나무(Corylus heterophylla Fisch. ex
Trautv.), 국수나무(Stephanandra incisa (Thunb.) Zabel) 등 이 흔하게 발견되며 소태나무(Picrasma quassioides (D. Don) Benn.)와 산복사도 자라고 있었다. 하지만 본 산은 자연휴양림, 임도 개발, 경작 등의 이유로 인위적인 훼손 이 많고 사람의 접근이 많아 질경이(Plantago asiatica L.), 바랭이(Digitaria sanguinalis (L.) Scop.), 돌피(Echinochloa crus-galli (L.) P. Beauv.), 애기똥풀(Chelidonium majus var. asiaticum (H. Hara) Ohwi) 등 도로변이나 트인 곳에서 자 라는 식물이 흔히 나타났고, 달맞이꽃(Oenothera odorata Jacq.), 끈끈이대나물(Silene armeria L.), 돼지풀, 족제비 싸리(Amorpha fruticosa L.) 등의 귀화식물이 아주 흔하게 분포하였다. 또한 조림을 위해 식재된 수종이 많았는데, 일본잎갈나무, 편백(Chamaecyparis obtusa (Siebold \& Zucc.) Endl.), 전나무(Abies holophylla Maxim.)뿐만 아니 라, 현재는 사라졌으나 옛 가마골터와 마을이 있었던 흔 적으로 보이는 감나무(Diospyros kaki Thunb.), 고욤나무 (Diospyros lotus L.), 개살구나무(Prunus mandshurica var. glabra Nakai) 등과 함께, 최근에 자연휴양림이 조성되면 서 식재된 병꽃나무(Weigela subsessilis (Nakai) L. H. Bailey), 화살나무(Euonymus alatus (Thunb.) Siebold), 산수 국(Hydrangea serrata f. acuminata (Siebold \& Zucc.) E. H. Wilson)도 흔히 볼 수 있었다. 습지 비오톱 근처에는 물가 에서 잘 자라는 버드나무(Salix koreensis Andersson), 신나 무(Acer tataricum subsp. ginnala (Maxim.) Wesm.), 물푸레 나무 등의 수목식생과 뱀딸기(Duchesnea chrysantha (Zoll. \& Moritzi) Miq.), 물봉선(Impatiens textori Miq.), 고 마리(Polygonum thunbergii Siebold \& Zucc.), 개망초, 여뀌 류 등의 초본식생이 번성하고 있고, 계곡을 따라 올라가 는 등산로 주변에서는 앉은부채(Symplocarpus renifolius Schott ex Tzvelev)가 군락을 이루고 있다. 정광산의 식물 상은 기존에 Choi et al. (2001), Ko and Shin (2009) 등에 의해 이루어진 경기도 중부지방에 대한 식물상 조사와

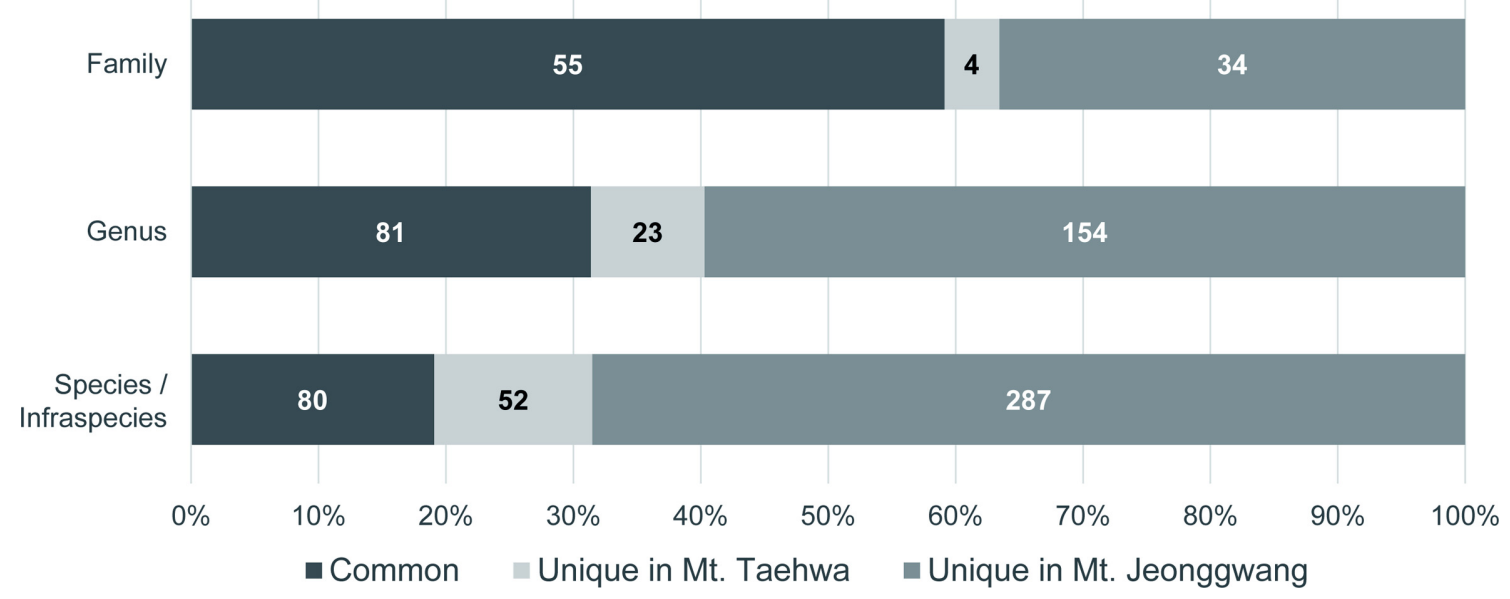

Fig. 2. The comparison of florae of Jeonggwangsan and Taehwasan Mts. in different taxonomic ranks. 
크게 다르지 않은 결과를 보여주었다. 특히 정광산과 인 접해있는 태화산의 경우 Choi et al. (2001)에 의해 조사된 결과 신갈나무, 산초나무, 생강나무, 고추나무(Staphylea bumalda DC.) 등의 수목식생과 윤판나물(Disporum uniflorum Baker), 앉은부채, 우산나물(Syneilesis palmata (Thunb.) Maxim.) 등의 초본식생이 자연식생에서 관찰되 고 잣나무와 일본잎갈나무 조림지가 조성되어 있음을 보여주며 정광산의 식물상과 아주 유사한 식물상 및 식 생환경을 보여주었다. 실제로 태화산과 정광산의 식물 상을 비교해본 결과 태화산에서 보고된 분류군 중 $60.6 \%$ 가 정광산에서도 확인되었고, 특히 해당 분류군이 속한 과의 경우 $93.2 \%$, 속의 경우 $77.9 \%$ 가 정광산에서도 확인 되었다(Fig. 2).

\section{생태학적 중요성}

정광산은 도시 지역에 가깝게 인접해 있는 도시산림 지역으로, 사람들의 접근이 쉽고 크고 작은 개발이 이루 어지고 있기 때문에 산림지역이 쉽게 훼손될 수 있다. 특 히 초부리 방면 일부 사면으로는 벌목으로 인해 주요 수 목식생이 크게 훼손되어 있었고, 이로 인해 토양이 노출 되어 건조해져서 초본식생 역시 기존의 계곡음지식생에 서 나지식생으로 바뀌어가고 있는 추세였다. 정광산 일 대는 동서로 큰 강줄기가 흐르며 산에도 크고 작은 계곡 을 따라 끊임없이 물줄기가 흐른다. 도시산림지역임에 도 불구하고 이 물줄기를 따라 다양한 식물종이 출현하 였을 뿐만 아니라 식물구계학적특정식물 등의 주요식물 들이 자생하고 있었기 때문에 생태학적으로 큰 의미가 있다고 판단된다. 또한 Jo and Ahn (2000)의 연구에서 용 인시 일대의 신갈나무를 포함한 참나무류가 우점하는 온대중부활엽수림은 도시 지역에서 발생하는 대기 중 탄소를 효과적으로 저장하여 대기탄소농도를 저감하는 데 큰 효과를 가지고 있다고 확인되어, 정광산 일대의 자 연수목은 도시생태계에서도 큰 비중을 차지하고 있다고 할 수 있다.

정광산에 조성된 용인자연휴양림에는 숲길을 따라 정 광산에 자생하는 식물들이 관리되고 있을 뿐 아니라 비오 톱을 조성하여 수계음지식생이 잘 보존될 수 있도록 구성 되어 있어, 용인자연휴양림을 중심으로 한 생태 보전 및 관찰을 통해 정광산의 생태계를 보존할 수 있을 것으로 기대한다.

ORCID: Ji-Hyeon JEON https://orcid.org/0000-0003-4028096X; Myong-Suk CHO https://orcid.org/0000-0003-23625217; Hee-Young GIL https://orcid.org/0000-0003-3714-0827; Seon-Hee KIM https://orcid.org/0000-0003-2032-1971; Petra JUNES (https://orcid.org/0000-0001-7341-3920); Hee-Seung SEO https://orcid.org/0000-0001-5162-070X; Seung-Chul KIM https://orcid.org/0000-0003-0559-6782

\section{Acknowledgments}

The earlier version of this manuscript was greatly improved by helpful comments and suggestions from two anonymous reviewers and editorial members of the KJPT. This work was supported by a grant (NIBR201501202) from the National Institute of Biological Resources (NIBR) funded by the Ministry of Environment (MOE), Republic of Korea.

\section{Conflict of Interest}

The authors declare that there are no conflicts of interest.

\section{Literature Cited}

Chang, C. S., H. Kim and K. S. Chang, 2011. Illustrated Encyclopedia of Fauna \& Flora of Korea, Vol. 43, Woody Plants. Ministry of Education, Seoul, 511 pp. (in Korean)

Choi, B. N. 2016. The National Atlas of Korea II. National Geography Information Institute, Suwon. Pp. 81-82. (in Korean)

Choi, D.-Y., C.-S. Chang, J. Y. Kim, J.-I. Jeon, H. Kim, W.-K. Min and U. Kang. 2001. Flora of Province Gyonggi-do. Bulletin of The Arboretum Seoul National University 21: 25-76. (in Korean)

Chung, G. Y., K. S. Chang, J.-M. Chung, H. J. Choi, W.-K. Paik and J.-O. Hyun. 2017. A checklist of endemic plants on the Korean Peninsula. Korean Journal of Plant Taxonomy 47: 264-288. (in Korean)

Flora of Korea Editorial Committee. 2007. The Genera of Vascular Plants of Korea. Academy Publishing Co., Seoul, 1482 pp.

Jo, H. K. and T. W. Ahn. 2000. Indicators of carbon storage and uptake by tree growth in natural ecosystem. Korean Journal of Envionment and Ecology 14: 175-182. (in Korean)

Kim, C. Y. 2009. Flora. Retrieved Oct. 22, 2018, available from $\mathrm{http}$ //yongin.grandculture.net. (in Korean)

Ko, S.-C. and Y.-H. Shin. 2009. Flora of middle part in Gyeonggi Province. The Korean Journal of Plant Resources 22: 49-70. (in Korean)

Korea National Arboretum and The Korean Society of Plant Taxonomists. 2007. A Synonymic List of Vascular Plant in Korea. Korea National Arboretum, Pocheon, 534 pp. (in Korean)

Kwon, D. H. 2009. Geology. Retrieved Oct. 22, 2018, available from http://yongin.grandculture.net. (in Korean)

Lee, T. B., 2003. Coloured Flora of Korea. Hyangmunsa, Seoul, Vol. 1, 914 pp, Vol. 2, 910 pp. (in Korean)

Lee, Y. N. 2006. New Flora of Korea. Kyohaksa, Seoul, Vol. 1, 975 pp, Vol. 2, 885 pp. (in Korean)

Lee, C. S. and K. H. Lee. 2015. Pteridophytes of Korea: Lyco- 
phytes \& Ferns. Geobook, Seoul, 471 pp. (in Korean)

Ministry of Environment and National Institute of Environmental Research. 2014. The fourth National Natural Environment Research Guidelines. Ministry of Environment and National Institute of Environmental Research, Gwacheon \& Incheon. Pp. 173-226. (in Korean)

National Institute of Biological Resources. 2012. Red Data Book of Endangered Vascular Plants in Korea. National Institute of Biological Resources, Incheon, 390 pp. (in Korean)

National Institute of Biological Resources. 2014. Korean Red List of Threatened Species. 2nd ed. National Institute of Biological Resources, Incheon, 242 pp.

National Institute of Biological Resources. 2016. Revision of the
Control List of Indigenous/Endemic Species of Korea. National Institute of Biological Resources, Incheon. Pp. 716759. (in Korean)

National Institute of Biological Resources. 2018. National List of Species of Korea. Retrived Oct. 16, 2018, available from http:/ /kbr.go.kr. (in Korean)

Oh, Y. C. 2006. Korean Caricoideae of Cyperaceae. Sungshin Women's University Press, Seoul, 404 pp. (in Korean)

Park, S. H., Y. M. Lee, S. Y. Jeong, K. S. Chang, U. Kang, S. S. Jung and J. C. Yang. 2011. Illustrated Grasses of Korea (Revised and Enlarged Edition). Korea National Arboretum, Pocheon, 600 pp. (in Korean)

\title{
정광산(용인시)의 관속식물상
}

\author{
전지현 · 조명숙 · 길희영1 · 김선희 · Petra JUNES · 서희승 · 김승철* \\ 성균관대학교 생명과학과, ${ }^{1}$ 국립수목원 산림생물다양성연구과
}

적 요: 경기도 용인시에 위치하는 정광산의 관속식물상을 조사하고 이에 분포하는 주요식물을 확인하였다. 본 조사는 2015년 5월부터 2016년 9월까지 총 14회에 걸쳐 이루어졌으며, 조사 결과 정광산에서 총 89과 234속 323종 6아종 34변종 4품종의 367분류군의 관속식물 분포가 확인되었다. 이 중 한국특산식물은 8 분류 군이 확인되었고, 식물구계학적 특정식물은 IV등급 4분류군, III등급 4분류군, II등급 2 분류군, I등급 9분류군 으로 총 19 분류군이 확인되었다. 국외반출 승인대상 식물은 59 분류군이 확인되었다. 적색목록 식물로는 준 위협종(Near Threatened, NT)으로 께묵 1분류군, 관심대상종(Least Concern, LC)으로 금붓꽃 1분류군으로 총 2 분류군이 확인되었다. 귀화식물로는 개망초, 돼지풀, 붉은서나물 등을 포함하여 27 분류군이 확인되었다.

주요어: 정광산, 식물상, 특산식물, 식물구계학적특정식물, 귀화식물 
Appendix 1. The list of vascular plants in Jeonggwangsan Mt.

\begin{tabular}{|c|c|c|c|}
\hline Taxon & Korean name & $\begin{array}{l}\text { Voucher } \\
\text { Number }\end{array}$ & $\begin{array}{l}\text { Export } \\
\text { regulation }\end{array}$ \\
\hline \multicolumn{4}{|l|}{ Equisetaceae 속새과 } \\
\hline Equisetum arvense $\mathrm{L}$. & 쇠뜨기 & NIBRVP 0000580573 & \\
\hline \multicolumn{4}{|l|}{ Dennstaedtiaceae 잔고사리과 } \\
\hline Dennstaedtia wilfordii (T. Moore) H. Christ & 황고사리 & NIBRVP 0000580743 & \\
\hline \multicolumn{4}{|l|}{ Athyriaceae 개고사리과 } \\
\hline Athyrium yokoscense (Franch. \& Sav.) H. Christ & 뱀고사리 & NIBRVP 0000550400 & \\
\hline \multicolumn{4}{|l|}{ Dryopteridaceae 관중과 } \\
\hline Dryopteris bissetiana (Baker) C. Chr. & 산족제비고사리 & NIBRVP 0000580659 & \\
\hline Dryopteris chinensis (Baker) Koidz. & 가는잎족제비고사리 & NIBRVP 0000580746 & \\
\hline Dryopteris uniformis (Makino) Makino & 곰비늘고사리 & NIBRVP 0000580707 & \\
\hline Polystichum tripteron (Kunze) C. Presl & 십자고사리 & NIBRVP 0000580710 & \\
\hline \multicolumn{4}{|l|}{ Pinaceae 소나무과 } \\
\hline Larix kaempferi (Lamb.) Carrière & 일본잎갈나무 (Cultivated) & NIBRVP 0000535773 & \\
\hline Pinus koraiensis Siebold \& Zucc. & 잣나무 & NIBRVP 0000580670 & $\mathrm{O}$ \\
\hline \multicolumn{4}{|l|}{ Lauraceae 녹나무과 } \\
\hline Lindera obtusiloba Blume & 생강나무 & NIBRVP 0000535475 & \\
\hline \multicolumn{4}{|l|}{ Aristolochiaceae 쥐방울덩굴과 } \\
\hline Asarum sieboldii Miq. & 족도리풀 & NIBRVP 0000535815 & \\
\hline \multicolumn{4}{|l|}{ Ranunculaceae 미나리아재비과 } \\
\hline Aconitum jaluense Kom. & 투구꽃 & NIBRVP 0000550460 & \\
\hline Aconitum pseudolaeve Nakai & 진범 & NIBRVP 0000550338 & $\mathrm{O}$ \\
\hline Clematis apiifolia DC. & 사위질빵 & NIBRVP 0000603705 & \\
\hline Clematis heracleifolia DC. & 병조희풀 & NIBRVP 0000550445 & \\
\hline Clematis patens C. Morren \& Decne. & 큰꽃으아리 & NIBRVP 0000550384 & $\mathrm{O}$ \\
\hline Clematis terniflora var. mandshurica (Rupr.) Ohwi & 으아리 & NIBRVP 0000535863 & \\
\hline Ranunculus chinensis Bunge & 젓가락나물 & NIBRVP 0000535826 & \\
\hline Thalictrum filamentosum Maxim. & 산뀡의다리 & NIBRVP 0000535969 & \\
\hline Thalictrum uchiyamae Nakai & 자주꿩의다리 & NIBRVP 0000550325 & $\mathrm{O}$ \\
\hline Thalictrum kemense var. hypoleucum (Siebold \& Zucc.) Kitag. & 좀꿩의다리 & NIBRVP 0000550503 & \\
\hline \multicolumn{4}{|l|}{ Menispermaceae 새모래덩굴과 } \\
\hline Cocculus trilobus (Thunb.) DC. & 댕댕이덩굴 & NIBRVP 0000535850 & \\
\hline Menispermum dauricum DC. & 새모래덩굴 & NIBRVP 0000535818 & \\
\hline \multicolumn{4}{|l|}{ Lardizabalaceae 으름덩굴과 } \\
\hline Akebia quinata (Houtt.) Decne. & 으름덩굴 & NIBRVP 0000535488 & \\
\hline \multicolumn{4}{|l|}{ Papaveraceae 양귀비과 } \\
\hline Chelidonium majus var. asiaticum (H. Hara) Ohwi & 애기똥풀 & NIBRVP 0000535494 & \\
\hline \multicolumn{4}{|l|}{ Fumariaceae 현호색과 } \\
\hline Corydalis pauciovulata Ohwi & 선괴불주머니 & NIBRVP 0000550345 & \\
\hline Corydalis remota Fisch. ex Maxim. & 현호색 & NIBRVP 0000535816 & \\
\hline
\end{tabular}


Appendix 1. Continued-

\begin{tabular}{|c|c|c|c|}
\hline Taxon & Korean name & $\begin{array}{l}\text { Voucher } \\
\text { Number }\end{array}$ & $\begin{array}{c}\text { Export } \\
\text { regulation }\end{array}$ \\
\hline Corydalis speciosa Maxim. & 산괴불주머니 & NIBRVP 0000535495 & \\
\hline Corydalis ternata (Nakai) Nakai & 들현호색 & NIBRVP 0000580595 & \\
\hline Corydalis turtschaninovii Besser & 조선현호색 & NIBRVP 0000580596 & \\
\hline \multicolumn{4}{|l|}{ Cannabaceae 삼과 } \\
\hline Humulus japonicus Siebold \& Zucc. & 환삼덩굴 & NIBRVP 0000550308 & \\
\hline \multicolumn{4}{|l|}{ Moraceae 뽛나무과 } \\
\hline Broussonetia kazinoki Siebold \& Zucc. & 닥나무 & NIBRVP 0000580704 & $\mathrm{O}$ \\
\hline Morus bombycis Koidz. & 산뽕나무 & NIBRVP 0000535775 & \\
\hline \multicolumn{4}{|l|}{ Urticaceae 쐐기풀과 } \\
\hline Boehmeria spicata (Thunb.) Thunb. & 좀깨잎나무 & NIBRVP 0000550327 & \\
\hline Pilea mongolica Wedd. & 모시물통이 & NIBRVP 0000550475 & \\
\hline Pilea pumila (L.) A. Gray & 큰물통이 & NIBRVP 0000550506 & \\
\hline \multicolumn{4}{|l|}{ Fagaceae 참나무과 } \\
\hline Castanea crenata Siebold \& Zucc. & 밤나무 & NIBRVP 0000535836 & \\
\hline Quercus acutissima Carruth. & 상수리나무 & NIBRVP 0000550284 & \\
\hline Quercus aliena Blume & 갈참나무 & NIBRVP 0000550279 & \\
\hline Quercus dentata Thunb. & 떡갈나무 & NIBRVP 0000550441 & \\
\hline Quercus mongolica Fisch. ex Ledeb. & 신갈나무 & NIBRVP 0000580612 & \\
\hline Quercus serrata Murray & 졸참나무 & NIBRVP 0000580751 & \\
\hline Quercus variabilis Blume & 굴참나무 & NIBRVP 0000550416 & \\
\hline Quercus x dentatomongolica Nakai & 떡신갈나무 & NIBRVP 0000603676 & \\
\hline \multicolumn{4}{|l|}{ Betulaceae 자작나무과 } \\
\hline Carpinus cordata Blume & 까치박달 & NIBRVP 0000603660 & \\
\hline Corylus heterophylla Fisch. ex Trautv. & 난티잎개암나무 & NIBRVP 0000580762 & \\
\hline Corylus sieboldiana var. mandshurica (Maxim.) C. K. Schneid. & 물개암나무 & NIBRVP 0000603653 & \\
\hline \multicolumn{4}{|l|}{ Phytolaccaceae 자리공과 } \\
\hline Phytolacca americana $\mathrm{L}$. & 미국자리공 & NIBRVP 0000550493 & \\
\hline \multicolumn{4}{|l|}{ Chenopodiaceae 명아주과 } \\
\hline Chenopodium ficifolium Sm. & 좀명아주 & NIBRVP 0000550424 & \\
\hline \multicolumn{4}{|l|}{ Amaranthaceae 비름과 } \\
\hline Achyranthes japonica (Miq.) Nakai & 쇠무릎 & NIBRVP 0000550318 & \\
\hline Amaranthus deflexus L. & 눈비름 & NIBRVP 0000550510 & \\
\hline Amaranthus retroflexus $\mathrm{L}$. & 털비름 & NIBRVP 0000603662 & \\
\hline \multicolumn{4}{|l|}{ Caryophyllaceae 석죽과 } \\
\hline Cerastium holosteoides var. hallaisanense (Nakai) M. Mizush. & 점나도나물 & NIBRVP 0000535777 & \\
\hline Cucubalus baccifer var. japonicus Miq. & 덩굴별꽃 & NIBRVP 0000550333 & \\
\hline Dianthus chinensis L. & 패랭이꽃 & NIBRVP 0000550366 & $\mathrm{O}$ \\
\hline Pseudostellaria heterophylla (Miq.) Pax & 개별꽃 & NIBRVP 0000535496 & \\
\hline Silene armeria $\mathrm{L}$. & 끈끈이대나물 & NIBRVP 0000603763 & \\
\hline
\end{tabular}


Appendix 1. Continued.

\begin{tabular}{|c|c|c|c|}
\hline Taxon & Korean name & $\begin{array}{l}\text { Voucher } \\
\text { Number }\end{array}$ & $\begin{array}{c}\text { Export } \\
\text { regulation }\end{array}$ \\
\hline Silene firma Siebold \& Zucc. & 장구채 & NIBRVP 0000550492 & \\
\hline Silene seoulensis Nakai & 가는장구채 & NIBRVP 0000550351 & \\
\hline Stellaria aquatica (L.) Scop. & 쇠별꽃 & NIBRVP 0000580614 & \\
\hline \multicolumn{4}{|l|}{ Polygonaceae 마디풀과 } \\
\hline Polygonum filiforme Thunb. & 이삭여뀌 & NIBRVP 0000550296 & \\
\hline Polygonum hydropiper $\mathrm{L}$. & 여뀌 & NIBRVP 0000603741 & \\
\hline Polygonum japonicum var. conspicuum Nakai & 꽃여뀌 & NIBRVP 0000603742 & \\
\hline Polygonum lapathifolium L. & 흰여뀌 & NIBRVP 0000550496 & \\
\hline Polygonum longisetum Bruijn & 개여뀌 & NIBRVP 0000535972 & \\
\hline Polygonum nepalense Meisn. & 산여뀌 & NIBRVP 0000603755 & \\
\hline Polygonum perfoliatum (L.) L. & 며느리배꼽 & NIBRVP 0000603753 & \\
\hline Polygonum posumbu Buch.-Ham. ex D. Don & 장대여뀌 & NIBRVP 0000550473 & \\
\hline Polygonum sagittatum $\mathrm{L}$. & 미꾸리낚시 & NIBRVP 0000550494 & \\
\hline Polygonum senticosum (Meisn.) Franch. \& Sav. & 며느리밑씻개 & NIBRVP 0000535968 & \\
\hline Polygonum thunbergii Siebold \& Zucc. & 고마리 & NIBRVP 0000550471 & \\
\hline Polygonum viscoferum Makino & 끈끈이여뀌 & NIBRVP 0000550509 & \\
\hline Rumex acetosa $\mathrm{L}$. & 수영 & NIBRVP 0000550291 & \\
\hline Rumex crispus $\mathrm{L}$. & 소리쟁이 & NIBRVP 0000535852 & \\
\hline \multicolumn{4}{|l|}{ Actinidiaceae 다래나무과 } \\
\hline Actinidia arguta (Siebold \& Zucc.) Planch. ex Miq. & 다래 & NIBRVP 0000550282 & $\mathrm{O}$ \\
\hline Actinidia polygama (Siebold \& Zucc.) Maxim. & 개다래 & NIBRVP 0000550394 & \\
\hline \multicolumn{4}{|l|}{ Clusiaceae 물레나물과 } \\
\hline Hypericum ascyron $\mathrm{L}$. & 물레나물 & NIBRVP 0000550485 & \\
\hline Hypericum erectum Thunb. & 고추나물 & NIBRVP 0000550324 & \\
\hline \multicolumn{4}{|l|}{ Tiliaceae 피나무과 } \\
\hline Corchoropsis psilocarpa Harms \& Loes. & 까치깨 & NIBRVP 0000603740 & \\
\hline Corchoropsis tomentosa (Thunb.) Makino & 수까치깨 & NIBRVP 0000550298 & \\
\hline Tilia mandshurica Rupr. \& Maxim. & 찰피나무 & NIBRVP 0000580663 & \\
\hline \multicolumn{4}{|l|}{ Violaceae 제비꽃과 } \\
\hline Viola acuminata Ledeb. & 졸방제비꽃 & NIBRVP 0000535492 & \\
\hline Viola albida Palib. & 태백제비꽃 & NIBRVP 0000580640 & $\mathrm{O}$ \\
\hline Viola albida var. chaerophylloides (Regel) F. Maek. & 남산제비꽃 & NIBRVP 0000535499 & \\
\hline Viola keiskei Miq. & 잔털제비꽃 & NIBRVP 0000580581 & \\
\hline Viola mandshurica W. Becker & 제비꽃 & NIBRVP 0000603778 & \\
\hline Viola phalacrocarpa Maxim. & 털제비꽃 & NIBRVP 0000535639 & \\
\hline Viola rossii Hemsl. & 고깔제비꽃 & NIBRVP 0000580609 & \\
\hline Viola variegata Fisch. ex Link & 알록제비꽃 & NIBRVP 0000535767 & \\
\hline Viola verecunda A. Gray & 콩제비꽃 & NIBRVP 0000550315 & \\
\hline Viola tokubuchiana var. takedana f. variegata F.Maek. & 줄민둥뫼제비꽃 & NIBRVP 0000580673 & \\
\hline
\end{tabular}


Appendix 1. Continued:

\begin{tabular}{|c|c|c|c|}
\hline Taxon & Korean name & $\begin{array}{l}\text { Voucher } \\
\text { Number }\end{array}$ & $\begin{array}{l}\text { Export } \\
\text { regulation }\end{array}$ \\
\hline \multicolumn{4}{|l|}{ Salicaceae 버드나무과 } \\
\hline Salix gracilistyla Miq. & 갯버들 & NIBRVP 0000580605 & \\
\hline Salix koriyanagi Kimura ex Goerz & 키버들 & NIBRVP 0000580606 & $\mathrm{O}$ \\
\hline \multicolumn{4}{|l|}{ Brassicaceae 십자화과 } \\
\hline Arabis glabra $(\mathrm{L}$.$) Bernh.$ & 장대나물 & NIBRVP 0000535830 & \\
\hline Barbarea orthoceras Ledeb. & 나도냉이 & NIBRVP 0000550514 & \\
\hline Capsella bursa-pastoris (L.) Medik. & 냉이 & NIBRVP 0000580585 & \\
\hline Cardamine fallax (O. E. Schulz) Nakai & 좁쌀냉이 & NIBRVP 0000535642 & \\
\hline Cardamine flexuosa With. & 황새냉이 & NIBRVP 0000535645 & \\
\hline Cardamine leucantha (Tausch) O. E. Schulz & 미나리냉이 & NIBRVP 0000535768 & $\mathrm{O}$ \\
\hline Draba nemorosa $\mathrm{L}$. & 꽃다지 & NIBRVP 0000535685 & \\
\hline Rorippa indica (L.) Hiern & 개갓냉이 & NIBRVP 0000603712 & \\
\hline Rorippa palustris (L.) Besser & 속속이풀 & NIBRVP 0000535812 & \\
\hline \multicolumn{4}{|l|}{ Ericaceae 진달래과 } \\
\hline Rhododendron mucronulatum Turcz. & 진달래 & NIBRVP 0000550419 & \\
\hline Rhododendron schlippenbachii Maxim. & 철쭉 & NIBRVP 0000550414 & $\mathrm{O}$ \\
\hline \multicolumn{4}{|l|}{ Pyrolaceae 노루발과 } \\
\hline Pyrola japonica Klenze ex Alef. & 노루발 & NIBRVP 0000603658 & \\
\hline \multicolumn{4}{|l|}{ Ebenaceae 감나무과 } \\
\hline Diospyros lotus L. & 고욤나무 & NIBRVP 0000535865 & \\
\hline \multicolumn{4}{|l|}{ Styracaceae 때죽나무과 } \\
\hline Styrax japonicus Siebold \& Zucc. & 때죽나무 & NIBRVP 0000535838 & $\mathrm{O}$ \\
\hline Styrax obassia Siebold \& Zucc. & 쪽동백나무 & NIBRVP 0000535866 & $\mathrm{O}$ \\
\hline \multicolumn{4}{|l|}{ Symplocaceae 노린재나무과 } \\
\hline Symplocos sawafutagi Nagam. & 노린재나무 & NIBRVP 0000535095 & $\mathrm{O}$ \\
\hline \multicolumn{4}{|l|}{ Primulaceae 앵초과 } \\
\hline Androsace umbellata (Lour.) Merr. & 봄맞이꽃 & NIBRVP 0000535776 & \\
\hline Lysimachia clethroides Duby & 큰까치수염 & NIBRVP 0000550378 & \\
\hline Lysimachia davurica Ledeb. & 좁쌀풀 & NIBRVP 0000580729 & \\
\hline Primula sieboldii E. Morren & 앵초 & NIBRVP 0000580603 & $\mathrm{O}$ \\
\hline \multicolumn{4}{|l|}{ Hydrangeaceae 수국과 } \\
\hline Deutzia uniflora Shirai & 매화말발도리 & NIBRVP 0000535820 & $\mathrm{O}$ \\
\hline Philadelphus schrenkii Rupr. & 고광나무 & NIBRVP 0000535636 & $\mathrm{O}$ \\
\hline Philadelphus tenuifolius Rupr. ex Maxim. & 엷은잎고광나무 & NIBRVP 0000580709 & \\
\hline \multicolumn{4}{|l|}{ Grossulariaceae 까치밥나무과 } \\
\hline Ribes fasciculatum var. chinense Maxim. & 까마귀밥나무 & NIBRVP 0000550370 & \\
\hline \multicolumn{4}{|l|}{ Crassulaceae 돌나물과 } \\
\hline Sedum aizoon $\mathrm{L}$. & 가는기린초 & NIBRVP 0000550417 & \\
\hline Sedum kamtschaticum Fisch. \& C. A. Mey. & 기린초 & NIBRVP 0000603646 & $\mathrm{O}$ \\
\hline Sedum sarmentosum Bunge & 돌나물 & NIBRVP 0000535840 & \\
\hline
\end{tabular}


Appendix 1. Continued.

\begin{tabular}{|c|c|c|c|}
\hline Taxon & Korean name & $\begin{array}{l}\text { Voucher } \\
\text { Number }\end{array}$ & $\begin{array}{l}\text { Export } \\
\text { regulation }\end{array}$ \\
\hline \multicolumn{4}{|l|}{ Saxifragaceae 범의귀과 } \\
\hline Chrysosplenium japonicum (Maxim.) Makino & 산괭이눈 & NIBRVP 0000580602 & \\
\hline \multicolumn{4}{|l|}{ Rosaceae 장미과 } \\
\hline Agrimonia pilosa Ledeb. & 짚신나물 & NIBRVP 0000603648 & \\
\hline Aria alnifolia (Siebold \& Zucc.) Decne. & 팥배나무 & NIBRVP 0000550444 & $\mathrm{O}$ \\
\hline Crataegus pinnatifida Bunge & 산사나무 & NIBRVP 0000535640 & $\mathrm{O}$ \\
\hline Duchesnea chrysantha (Zoll. \& Moritzi) Miq. & 뱀딸기 & NIBRVP 0000535825 & \\
\hline Geum aleppicum Jacq. & 큰뱀무 & NIBRVP 0000550372 & \\
\hline Malus baccata (L.) Borkh. & 야광나무 & NIBRVP 0000535479 & $\mathrm{O}$ \\
\hline Potentilla anemonifolia Lehm. & 가락지나물 & NIBRVP 0000580756 & \\
\hline Potentilla fragarioides $\mathrm{L}$. & 양지꽃 & NIBRVP 0000535861 & \\
\hline Potentilla freyniana Bornm. & 세잎양지꽃 & NIBRVP 0000535493 & \\
\hline Potentilla supina $\mathrm{L}$. & 개소시랑개비 & NIBRVP 0000580615 & \\
\hline Prunus davidiana (Carrière) Franch. & 산복사 (Cultivated) & NIBRVP 0000580623 & \\
\hline Prunus japonica var. nakaii (H. Lév.) Rehder & 이스라지나무 & NIBRVP 0000550407 & \\
\hline Prunus persica (L.) Batsch & 복숭아나무 (Cultivated) & NIBRVP 0000550283 & \\
\hline Prunus serrulata var. pubescens (Makino) Nakai & 잔털벚나무 & NIBRVP 0000535481 & \\
\hline Rosa multiflora Thunb. & 찔레나무 & NIBRVP 0000535823 & \\
\hline Rubus coreanus Miq. & 복분자딸기 & NIBRVP 0000580740 & $\mathrm{O}$ \\
\hline Rubus crataegifolius Bunge & 산딸기 & NIBRVP 0000535844 & \\
\hline Rubus parvifolius $\mathrm{L}$. & 멍석딸기 & NIBRVP 0000580703 & \\
\hline Rubus phoenicolasius Maxim. & 곰딸기 & NIBRVP 0000535849 & \\
\hline Spiraea prunifolia var. simpliciflora (Nakai) Nakai & 조팝나무 & NIBRVP 0000535829 & $\mathrm{O}$ \\
\hline Spiraea salicifolia $\mathrm{L}$. & 꼬리조팝나무 & NIBRVP 0000580730 & $\mathrm{O}$ \\
\hline Stephanandra incisa (Thunb.) Zabel & 국수나무 & NIBRVP 0000535828 & \\
\hline \multicolumn{4}{|l|}{ Fabaceae 콩과 } \\
\hline Albizia julibrissin Durazz. & 자귀나무 & NIBRVP 0000550385 & \\
\hline Amorpha fruticosa $\mathrm{L}$. & 족제비싸리 & NIBRVP 0000535847 & \\
\hline Amphicarpaea bracteata subsp. edgeworthii (Benth.) H. Ohashi & 새콩 & NIBRVP 0000550486 & \\
\hline Chamaecrista nomame (Siebold) H. Ohashi & 차풀 & NIBRVP 0000550305 & \\
\hline Desmodium podocarpum subsp. oxyphyllum (DC.) H. Ohashi & 도둑놈의갈고리 & NIBRVP 0000550478 & \\
\hline Glycine soja Siebold \& Zucc. & 돌콩 & NIBRVP 0000550319 & $\mathrm{O}$ \\
\hline Indigofera bungeana Walp. & 큰낭아초 & NIBRVP 0000603757 & \\
\hline Kummerowia striata (Thunb.) Schindl. & 매듭풀 & NIBRVP 0000550442 & \\
\hline Lathyrus davidii Hance & 활량나물 & NIBRVP 0000550413 & \\
\hline Lespedeza bicolor Turcz. & 싸리 & NIBRVP 0000550488 & $\mathrm{O}$ \\
\hline Lespedeza cuneata (Dum. Cours.) G. Don. & 비수리 & NIBRVP 0000603776 & $\mathrm{O}$ \\
\hline Lespedeza cyrtobotrya Miq. & 참싸리 & NIBRVP 0000603692 & \\
\hline Lespedeza thunbergii subsp. formosa (Vogel) H. Ohashi & 중국풀싸리 & NIBRVP 0000550328 & \\
\hline
\end{tabular}


Appendix 1. Continued.

\begin{tabular}{|c|c|c|c|}
\hline Taxon & Korean name & $\begin{array}{l}\text { Voucher } \\
\text { Number }\end{array}$ & $\begin{array}{c}\text { Export } \\
\text { regulation }\end{array}$ \\
\hline Lotus corniculatus var. japonicus Regel & 벌노랑이 & NIBRVP 0000603641 & \\
\hline Pueraria lobata (Willd.) Ohwi & 칡 & NIBRVP 0000550393 & \\
\hline Robinia pseudoacacia $\mathrm{L}$. & 아까시나무 & NIBRVP 0000580654 & \\
\hline Sophora flavescens Aiton & 고삼 & NIBRVP 0000550286 & \\
\hline Trifolium repens $\mathrm{L}$. & 토끼풀 & NIBRVP 0000535857 & \\
\hline Vicia unijuga A. Braun & 나비나물 & NIBRVP 0000550477 & \\
\hline Vicia venosa var. cuspidata Maxim. & 광릉갈퀴 & NIBRVP 0000603650 & \\
\hline Vigna angularis var. nipponensis (Ohwi) Ohwi \& H. Ohashi & 새팥 & NIBRVP 0000603736 & \\
\hline Vigna radiata $(\mathrm{L}.) \mathrm{R}$. Wilczek & 녹두 & NIBRVP 0000550311 & \\
\hline \multicolumn{4}{|l|}{ Elaeagnaceae 보리수나무과 } \\
\hline Elaeagnus umbellata Thunb. & 보리수나무 & NIBRVP 0000535771 & \\
\hline \multicolumn{4}{|l|}{ Lythraceae 부처꽃과 } \\
\hline Lythrum anceps (Koehne) Makino & 부처꽃 & NIBRVP 0000603706 & \\
\hline \multicolumn{4}{|l|}{ Onagraceae 바늘꽃과 } \\
\hline Circaea mollis Siebold \& Zucc. & 털이슬 & NIBRVP 0000550342 & \\
\hline Oenothera odorata Jacq. & 달맞이꽃 & NIBRVP 0000550290 & \\
\hline \multicolumn{4}{|l|}{ Alangiaceae 박쥐나무과 } \\
\hline Alangium platanifolium var. trilobum (Miq.) Ohwi & 박쥐나무 & NIBRVP 0000535848 & \\
\hline \multicolumn{4}{|l|}{ Cornaceae 충충나무과 } \\
\hline Cornus controversa Hemsl. & 층층나무 & NIBRVP 0000535075 & \\
\hline Cornus walteri Wangerin & 말채나무 & NIBRVP 0000580702 & \\
\hline \multicolumn{4}{|l|}{ Celastraceae 노박덩굴과 } \\
\hline Celastrus orbiculatus Thunb. & 노박덩굴 & NIBRVP 0000550440 & \\
\hline Euonymus alatus var. alatus f. ciliatodentatus Hiyama & 회잎나무 & NIBRVP 0000535772 & \\
\hline Euonymus hamiltonianus Wall. & 참빗살나무 & NIBRVP 0000550406 & $\mathrm{O}$ \\
\hline \multicolumn{4}{|l|}{ Euphorbiaceae 대극과 } \\
\hline Acalypha australis $\mathrm{L}$. & 깨풀 & NIBRVP 0000550304 & \\
\hline Phyllanthus ussuriensis Rupr. \& Maxim. & 여우주머니 & NIBRVP 0000603711 & \\
\hline Securinega suffruticosa (Pall.) Rehder & 광대싸리 & NIBRVP 0000535824 & \\
\hline \multicolumn{4}{|l|}{ Vitaceae 포도과 } \\
\hline Ampelopsis brevipedunculata (Maxim.) Trautv. & 개머루 & NIBRVP 0000535864 & \\
\hline Parthenocissus tricuspidata (Siebold \& Zucc.) Planch. & 담쟁이덩굴 & NIBRVP 0000550288 & \\
\hline Vitis amurensis Rupr. & 왕머루 & NIBRVP 0000550408 & $\mathrm{O}$ \\
\hline Vitis flexuosa Thunb. & 새머루 & NIBRVP 0000580666 & \\
\hline \multicolumn{4}{|l|}{ Staphyleaceae 고추나무과 } \\
\hline Staphylea bumalda DC. & 고추나무 & NIBRVP 0000535477 & \\
\hline \multicolumn{4}{|l|}{ Sapindaceae 무환자나무과 } \\
\hline Cardiospermum halicacabum L. & 풍선덩굴 (Cultivated) & NIBRVP 0000550314 & \\
\hline \multicolumn{4}{|l|}{ Aceraceae 단풍나무과 } \\
\hline Acer pictum var. mono (Maxim.) Franch. & 고로쇠나무 & NIBRVP 0000535497 & $\mathrm{O}$ \\
\hline
\end{tabular}


Appendix 1. Continued.

\begin{tabular}{|c|c|c|c|}
\hline Taxon & Korean name & $\begin{array}{l}\text { Voucher } \\
\text { Number }\end{array}$ & $\begin{array}{c}\text { Export } \\
\text { regulation }\end{array}$ \\
\hline Acer pseudosieboldianum (Pax) Kom. & 당단풍나무 & NIBRVP 0000535498 & \\
\hline Acer tataricum subsp. ginnala (Maxim.) Wesm. & 신나무 & NIBRVP 0000535081 & $\mathrm{O}$ \\
\hline \multicolumn{4}{|l|}{ Anacardiaceae 옻나무과 } \\
\hline Rhus javanica $\mathrm{L}$. & 붉나무 & NIBRVP 0000535476 & \\
\hline Toxicodendron trichocarpum (Miq.) Kuntze & 개옻나무 & NIBRVP 0000535842 & \\
\hline \multicolumn{4}{|l|}{ Simaroubaceae 소태나무과 } \\
\hline Picrasma quassioides (D. Don) Benn. & 소태나무 & NIBRVP 0000580669 & $\mathrm{O}$ \\
\hline \multicolumn{4}{|l|}{ Rutaceae 운향과 } \\
\hline Zanthoxylum schinifolium Siebold \& Zucc. & 산초나무 & NIBRVP 0000550397 & $\mathrm{O}$ \\
\hline \multicolumn{4}{|l|}{ Oxalidaceae 괭이밥과 } \\
\hline Oxalis corniculata $\mathrm{L}$. & 괭이밥 & NIBRVP 0000580626 & \\
\hline Oxalis obtriangulata Maxim. & 큰괭이밥 & NIBRVP 0000580713 & \\
\hline \multicolumn{4}{|l|}{ Geraniaceae 쥐손이풀과 } \\
\hline Geranium thunbergii Siebold ex Lindl. \& Paxton & 이질풀 & NIBRVP 0000550306 & $\mathrm{O}$ \\
\hline \multicolumn{4}{|l|}{ Balsaminaceae 봉선화과 } \\
\hline Impatiens nolitangere $\mathrm{L}$. & 노랑물봉선 & NIBRVP 0000550321 & \\
\hline Impatiens textori Miq. & 물봉선 & NIBRVP 0000550341 & $\mathrm{O}$ \\
\hline \multicolumn{4}{|l|}{ Araliaceae 두릅나무과 } \\
\hline Aralia cordata var. continentalis (Kitag.) Y. C. Chu & 독활 & NIBRVP 0000550468 & \\
\hline \multicolumn{4}{|l|}{ Apiaceae 미나리과 } \\
\hline Angelica dahurica (Fisch. ex Hoffm.) Benth. \& Hook. f. ex Franch. \& Sav. & 구릿대 & NIBRVP 0000550312 & \\
\hline Angelica decursiva (Miq.) Franch. \& Sav. & 바디나물 & NIBRVP 0000550505 & \\
\hline Heracleum moellendorffii Hance & 어수리 & NIBRVP 0000550377 & $\mathrm{O}$ \\
\hline Osmorhiza aristata (Thunb.) Rydb. & 긴사상자 & NIBRVP 0000580649 & \\
\hline Ostericum grosseserratum (Maxim.) Kitag. & 신감채 & NIBRVP 0000603695 & \\
\hline Peucedanum terebinthaceum (Fisch. ex Trevir.) Fisch. ex Turcz. & 기름나물 & NIBRVP 0000550404 & \\
\hline Pimpinella brachycarpa (Kom.) Nakai & 참나물 & NIBRVP 0000550326 & $\mathrm{O}$ \\
\hline Sanicula chinensis Bunge & 참반디 & NIBRVP 0000550301 & \\
\hline \multicolumn{4}{|l|}{ Gentianaceae 용담과 } \\
\hline Gentiana zollingeri Fawc. & 큰구슬붕이 & NIBRVP 0000535817 & \\
\hline \multicolumn{4}{|l|}{ Asclepiadaceae 박주가리과 } \\
\hline Metaplexis japonica (Thunb.) Makino & 박주가리 & NIBRVP 0000550294 & \\
\hline \multicolumn{4}{|l|}{ Solanaceae 가지과 } \\
\hline Solanum nigrum L. & 까마중 & NIBRVP 0000550285 & \\
\hline \multicolumn{4}{|l|}{ Convolvulaceae 메꽃과 } \\
\hline Calystegia hederacea (Thunb.) Makino & 애기메꽃 & NIBRVP 0000535851 & \\
\hline Calystegia sepium var. japonica (Thunb.) Makino & 메꽃 & NIBRVP 0000580678 & \\
\hline Cuscuta australis R. Br. & 실새삼 & NIBRVP 0000550289 & \\
\hline Cuscuta pentagona Engelm. & 미국실새삼 & NIBRVP 0000603721 & \\
\hline
\end{tabular}


Appendix 1. Continued.

\begin{tabular}{|c|c|c|c|}
\hline Taxon & Korean name & $\begin{array}{l}\text { Voucher } \\
\text { Number }\end{array}$ & $\begin{array}{c}\text { Export } \\
\text { regulation }\end{array}$ \\
\hline \multicolumn{4}{|l|}{ Boraginaceae 지치과 } \\
\hline Trigonotis peduncularis (Trevis.) Benth. ex Baker \& S. Moore & 꽃마리 & NIBRVP 0000535769 & \\
\hline Trigonotis radicans var. sericea (Maxim.) H. Hara & 참꽃마리 & NIBRVP 0000535483 & \\
\hline \multicolumn{4}{|l|}{ Verbenaceae 마편초과 } \\
\hline Callicarpa japonica Thunb. & 작살나무 & NIBRVP 0000535837 & \\
\hline Caryopteris divaricata Maxim. & 누린내풀 & NIBRVP 0000550339 & \\
\hline Clerodendrum trichotomum Thunb. & 누리장나무 & NIBRVP 0000550383 & $\mathrm{O}$ \\
\hline \multicolumn{4}{|l|}{ Phrymaceae 파리풀과 } \\
\hline Phryma leptostachya var. oblongifolia (Koidz.) Honda & 파리풀 & NIBRVP 0000550392 & \\
\hline \multicolumn{4}{|l|}{ Lamiaceae 꿀풀과 } \\
\hline Clinopodium chinense var. parviflorum (Kudo?) H. Hara & 층층이꽃 & NIBRVP 0000550335 & \\
\hline Clinopodium chinense var. shibetchense (H. Lév.) Koidz. & 산층층이 & NIBRVP 0000603696 & \\
\hline Elsholtzia ciliata (Thunb.) H. Hyl. & 향유 & NIBRVP 0000603686 & \\
\hline Elsholtzia splendens Nakai ex F. Maek. & 꽃향유 & NIBRVP 0000550362 & \\
\hline Isodon excisus (Maxim.) Kudo? & 오리방풀 & NIBRVP 0000550344 & \\
\hline Isodon inflexus (Thunb.) Kudo? & 산박하 & NIBRVP 0000603758 & \\
\hline Isodon japonicus (Burm. f.) H. Hara & 방아풀 & NIBRVP 0000550446 & \\
\hline Leonurus japonicus Houtt. & 익모초 & NIBRVP 0000550295 & \\
\hline Lycopus lucidus Turcz. ex Benth. & 쉽싸리 & NIBRVP 0000603665 & \\
\hline Meehania urticifolia (Miq.) Makino & 벌깨덩굴 & NIBRVP 0000535482 & \\
\hline Mosla dianthera (Buch.-Ham. ex Roxb.) Maxim. & 쥐깨풀 & NIBRVP 0000550430 & \\
\hline Mosla punctulata (J. F. Gmel.) Nakai & 들깨풀 & NIBRVP 0000550423 & \\
\hline Prunella asiatica Nakai & 꿀풀 & NIBRVP 0000580753 & $\mathrm{O}$ \\
\hline Scutellaria indica $\mathrm{L}$. & 골무꽃 & NIBRVP 0000535487 & \\
\hline Scutellaria insignis Nakai & 광릉골무꽃 & NIBRVP 0000535853 & $\mathrm{O}$ \\
\hline Scutellaria pekinensis var. transitra (Makino) H. Hara & 산골무꽃 & NIBRVP 0000603767 & \\
\hline Teucrium viscidum var. miquelianum (Maxim.) H. Hara & 덩굴곽향 & NIBRVP 0000603644 & \\
\hline \multicolumn{4}{|l|}{ Plantaginaceae 질경이과 } \\
\hline Plantago asiatica $\mathrm{L}$. & 질경이 & NIBRVP 0000535839 & \\
\hline \multicolumn{4}{|l|}{ Oleaceae 물푸레나무과 } \\
\hline Fraxinus rhynchophylla Hance & 물푸레나무 & NIBRVP 0000535474 & \\
\hline Ligustrum obtusifolium Siebold \& Zucc. & 쥐똥나무 & NIBRVP 0000535827 & \\
\hline \multicolumn{4}{|l|}{ Scrophulariaceae 현삼과 } \\
\hline Lindernia procumbens (Krock.) Borbás & 밭둑외풀 & NIBRVP 0000580676 & \\
\hline Mazus pumilus (Burm. f.) Steenis & 주름잎 & NIBRVP 0000535833 & \\
\hline Melampyrum roseum Maxim. & 꽃며느리밥풀 & NIBRVP 0000603693 & \\
\hline Paulownia coreana Uyeki & 오동나무 & NIBRVP 0000550320 & $\mathrm{O}$ \\
\hline Paulownia tomentosa (Thunb.) Steud. & 참오동나무 (Cultivated) & NIBRVP 0000580671 & \\
\hline Phtheirospermum japonicum (Thunb.) Kanitz & 나도송이풀 & NIBRVP 0000550467 & \\
\hline
\end{tabular}


Appendix 1. Continued.

\begin{tabular}{|c|c|c|c|}
\hline Taxon & Korean name & $\begin{array}{l}\text { Voucher } \\
\text { Number }\end{array}$ & $\begin{array}{c}\text { Export } \\
\text { regulation }\end{array}$ \\
\hline Scrophularia kakudensis Franch. & 큰개현삼 & NIBRVP 0000603718 & \\
\hline Veronica arvensis $\mathrm{L}$. & 선개불알풀 & NIBRVP 0000580621 & \\
\hline \multicolumn{4}{|l|}{ Campanulaceae 초롱꽃과 } \\
\hline Adenophora remotiflora (Siebold \& Zucc.) Miq. & 모시대 & NIBRVP 0000550352 & \\
\hline Asyneuma japonicum (Miq.) Briq. & 영아자 & NIBRVP 0000550330 & \\
\hline \multicolumn{4}{|l|}{ Rubiaceae 꼭두선이과 } \\
\hline Asperula odorata $\mathrm{L}$. & 선갈퀴 & NIBRVP 0000535834 & \\
\hline Galium spurium var. echinospermum (Wallr.) Hayek & 갈퀴덩굴 & NIBRVP 0000580630 & \\
\hline Galium verum var. asiaticum Nakai & 솔나물 & NIBRVP 0000603674 & \\
\hline Rubia akane Nakai & 꼭두선이 & NIBRVP 0000550436 & \\
\hline Rubia cordifolia var. pratensis Maxim. & 갈퀴꼭두선이 & NIBRVP 0000550346 & \\
\hline \multicolumn{4}{|l|}{ Diervillaceae 병꽃나무과 } \\
\hline Weigela subsessilis (Nakai) L. H. Bailey & 병꽃나무 & NIBRVP 0000535489 & $\mathrm{O}$ \\
\hline \multicolumn{4}{|l|}{ Caprifoliaceae 인동과 } \\
\hline Lonicera japonica Thunb. & 인동 & NIBRVP 0000535862 & \\
\hline Lonicera maackii (Rupr.) Maxim. & 괴불나무 & NIBRVP 0000550350 & $\mathrm{O}$ \\
\hline \multicolumn{4}{|l|}{ Viburnaceae 산분꽃나무과 } \\
\hline Viburnum dilatatum Thunb. & 가막살나무 & NIBRVP 0000535774 & \\
\hline \multicolumn{4}{|l|}{ Adoxaceae 연복초과 } \\
\hline Sambucus racemosa subsp. sieboldiana (Miq.) H. Hara & 딱총나무 & NIBRVP 0000535100 & $\mathrm{O}$ \\
\hline \multicolumn{4}{|l|}{ Valerianaceae 마타리과 } \\
\hline Patrinia villosa (Thunb.) Juss. & 뚝갈 & NIBRVP 0000550464 & \\
\hline \multicolumn{4}{|l|}{ Asteraceae 국화과 } \\
\hline Adenocaulon himalaicum Edgew. & 멸가치 & NIBRVP 0000550299 & \\
\hline Ainsliaea acerifolia Sch. Bip. & 단풍취 & NIBRVP 0000603679 & \\
\hline Ambrosia artemisiifolia $\mathrm{L}$. & 돼지풀 & NIBRVP 0000550323 & \\
\hline Artemisia keiskeana Miq. & 맑은대쑥 & NIBRVP 0000550435 & \\
\hline Artemisia princeps Pamp. & 丛 & NIBRVP 0000550303 & \\
\hline Artemisia stolonifera (Maxim.) Kom. & 넓은잎외잎쑥 & NIBRVP 0000550428 & \\
\hline Aster ageratoides Turcz. & 까실쑥부쟁이 & NIBRVP 0000550452 & \\
\hline Aster koraiensis Nakai & 벌개미취 (Cultivated) & NIBRVP 0000603746 & $\mathrm{O}$ \\
\hline Aster pilosus Willd. & 미국쑥부쟁이 & NIBRVP 0000550317 & \\
\hline Aster scaber Thunb. & 참취 & NIBRVP 0000550332 & \\
\hline Aster yomena (Kitam.) Honda & 쑥부쟁이 & NIBRVP 0000603723 & \\
\hline Atractylodes ovata (Thunb.) DC. & 삽주 & NIBRVP 0000603709 & \\
\hline Bidens frondosa $\mathrm{L}$. & 미국가막사리 & NIBRVP 0000550439 & \\
\hline Carduus crispus L. & 지느러미엉겅퀴 & NIBRVP 0000550375 & \\
\hline Carpesium abrotanoides $\mathrm{L}$. & 담배풀 & NIBRVP 0000603729 & \\
\hline Cirsium japonicum var. ussuriense (Regel) Kitam. & 엉겅퀴 & NIBRVP 0000535971 & \\
\hline
\end{tabular}


Appendix 1. Continued:

\begin{tabular}{|c|c|c|c|}
\hline Taxon & Korean name & $\begin{array}{l}\text { Voucher } \\
\text { Number }\end{array}$ & $\begin{array}{c}\text { Export } \\
\text { regulation }\end{array}$ \\
\hline Cirsium pendulum Fisch. ex DC. & 큰엉겅퀴 & NIBRVP 0000550313 & \\
\hline Conyza canadensis (L.) Cronquist & 망초 & NIBRVP 0000550363 & \\
\hline Crepidiastrum denticulatum (Houtt.) J. H. Pak \& Kawano & 이고들빼기 & NIBRVP 0000550438 & \\
\hline Crepidiastrum sonchifolium (Bunge) J. H. Pak \& Kawano & 고들빼기 & NIBRVP 0000535859 & \\
\hline Dendranthema boreale (Makino) Ling & 산국 & NIBRVP 0000550443 & $\mathrm{O}$ \\
\hline Erechtites hieracifolia (L.) Raf. ex DC. & 붉은서나물 & NIBRVP 0000550360 & \\
\hline Erigeron annuиs (L.) Pers. & 개망초 & NIBRVP 0000535822 & \\
\hline Eupatorium japonicum Thunb. & 등골나물 & NIBRVP 0000535846 & \\
\hline Eupatorium rugosum Houtt. & 서양등골나물 & NIBRVP 0000550470 & \\
\hline Galinsoga quadriradiata Ruiz \& Pav. & 털별꽃아재비 & NIBRVP 0000550316 & \\
\hline Hemistepta lyrata Bunge & 지칭개 & NIBRVP 0000535644 & \\
\hline Hieracium umbellatum $\mathrm{L}$. & 조밥나물 & NIBRVP 0000603766 & \\
\hline Hololeion maximowiczii Kitam. & 께묵 & NIBRVP 0000550512 & $\mathrm{O}$ \\
\hline Ixeris dentata f. amplifolia Hiyama & 흰씀바귀 & NIBRVP 0000580752 & \\
\hline Ixeris polycephala Cass. & 벌씀바귀 & NIBRVP 0000535813 & \\
\hline Lactuca indica var. laciniata (Houtt.) H. Hara & 왕고들빼기 & NIBRVP 0000550465 & \\
\hline Sigesbeckia glabrescens Makino & 진득찰 & NIBRVP 0000550513 & \\
\hline Solidago virgaurea subsp. asiatica Kitam. ex H. Hara & 미역취 & NIBRVP 0000550469 & $\mathrm{O}$ \\
\hline Sonchus asper (L.) Hill & 큰방가지똥 & NIBRVP 0000603768 & \\
\hline Syneilesis palmata (Thunb.) Maxim. & 우산나물 & NIBRVP 0000580749 & $\mathrm{O}$ \\
\hline Xanthium canadense Mill. & 큰도꼬마리 & NIBRVP 0000550356 & \\
\hline Youngia japonica (L.) DC. & 뽀리뱅이 & NIBRVP 0000535643 & \\
\hline Aster meyendorfii (Regel \& Maack) Voss & 개쑥부쟁이 & NIBRVP 0000550365 & \\
\hline \multicolumn{4}{|l|}{ Araceae 천남성과 } \\
\hline Arisaema amurense Maxim. & 둥근잎천남성 & NIBRVP 0000535491 & \\
\hline Arisaema amurense f. serratum (Nakai) Kitag. & 천남성 & NIBRVP 0000535490 & \\
\hline Arisaema peninsulae Nakai & 점백이천남성 & NIBRVP 0000580635 & \\
\hline \multicolumn{4}{|l|}{ Commelinaceae 닭의장풀과 } \\
\hline Commelina communis L. & 닭의장풀 & NIBRVP 0000603672 & \\
\hline Streptolirion volubile Edgew. & 덩굴닭의장풀 & NIBRVP 0000550336 & \\
\hline \multicolumn{4}{|l|}{ Juncaceae 골풀과 } \\
\hline Juncus effusus var. decipiens Buchenau & 골풀 & NIBRVP 0000535835 & \\
\hline Juncus tenuis Willd. & 길골풀 & NIBRVP 0000535973 & \\
\hline Luzula capitata Kom. & 뀡의밥 & NIBRVP 0000535860 & \\
\hline \multicolumn{4}{|l|}{ Cyperaceae 사초과 } \\
\hline Carex breviculmis $\mathrm{R} . \mathrm{Br}$. & 청사초 & NIBRVP 0000535638 & \\
\hline Carex japonica Thunb. & 개찌버리사초 & NIBRVP 0000535637 & \\
\hline Carex laevissima Nakai & 애괭이사초 & NIBRVP 0000535856 & \\
\hline Carex leiorhyncha C. A. Mey. & 산괭이사초 & NIBRVP 0000580627 & \\
\hline
\end{tabular}


Appendix 1. Continued.

\begin{tabular}{|c|c|c|c|}
\hline Taxon & Korean name & $\begin{array}{l}\text { Voucher } \\
\text { Number }\end{array}$ & $\begin{array}{c}\text { Export } \\
\text { regulation }\end{array}$ \\
\hline Carex nervata Franch. \& Sav. & 양지사초 & NIBRVP 0000580608 & \\
\hline Carex polyschoena H. Lév. \& Vaniot & 가지청사초 & NIBRVP 0000580607 & \\
\hline Cyperus amuricus Maxim. & 방동산이 & NIBRVP 0000550307 & \\
\hline Cyperus iria $\mathrm{L}$. & 참방동산이 & NIBRVP 0000550483 & \\
\hline Cyperus microiria Steud. & 금방동산이 & NIBRVP 0000603773 & \\
\hline Fimbristylis littoralis Gaudich. & 바람하늘지기 & NIBRVP 0000603724 & \\
\hline Kyllinga brevifolia Rottb. & 가시파대가리 & NIBRVP 0000603731 & \\
\hline \multicolumn{4}{|l|}{ Poaceae 화본과 } \\
\hline Agrostis clavata var. nukabo Ohwi & 겨이삭 & NIBRVP 0000535974 & \\
\hline Calamagrostis arundinacea (L.) Roth & 실새풀 & NIBRVP 0000550497 & \\
\hline Dactylis glomerata L. & 오리새 & NIBRVP 0000535858 & \\
\hline Diarrhena fauriei (Hack.) Ohwi & 광릉용수염풀 & NIBRVP 0000550389 & \\
\hline Digitaria sanguinalis (L.) Scop. & 바랭이 & NIBRVP 0000550425 & \\
\hline Echinochloa crus-galli (L.) P. Beauv. & 돌피 & NIBRVP 0000550368 & \\
\hline Echinochloa crus-galli var. praticola Ohwi & 좀돌피 & NIBRVP 0000603687 & \\
\hline Echinochloa oryzicola (Ard.) Fritsch & 논피 & NIBRVP 0000550500 & \\
\hline Eragrostis curvula (Schrad.) Nees & 능수참새그령 & NIBRVP 0000535854 & \\
\hline Eragrostis ferruginea (Thunb.) P. Beauv. & 그령 & NIBRVP 0000550456 & \\
\hline Festuca arundinacea Schreb. & 큰김의털 & NIBRVP 0000535831 & \\
\hline Festuca heterophylla Lam. & 사방김의털 & NIBRVP 0000550449 & \\
\hline Festuca ovina $\mathrm{L}$. & 김의털 & NIBRVP 0000550403 & \\
\hline Festuca rubra L. & 왕김의털 & NIBRVP 0000580763 & \\
\hline Lolium multiflorum Lam. & 쥐보리 & NIBRVP 0000580745 & \\
\hline Miscanthus sinensis Andersson & 억새 & NIBRVP 0000550499 & \\
\hline Muhlenbergia huegelii Trin. & 큰쥐꼬리새 & NIBRVP 0000550340 & \\
\hline Oplismenus undulatifolius (Ard.) Roem. \& Schult. & 주름조개풀 & NIBRVP 0000550462 & \\
\hline Panicum bisulcatum Thunb. & 개기장 & NIBRVP 0000550433 & \\
\hline Pennisetum alopecuroides (L.) Spreng. & 수크령 & NIBRVP 0000603770 & \\
\hline Poa viridula Palib. & 청포아풀 & NIBRVP 0000580643 & \\
\hline Setaria faberi R. A. W. Herrm. & 가을강아지풀 & NIBRVP 0000550361 & \\
\hline Setaria glauca (L.) P. Beauv. & 금강아지풀 & NIBRVP 0000550309 & \\
\hline Setaria viridis (L.) P. Beauv. & 강아지풀 & NIBRVP 0000550364 & \\
\hline Setaria x pycnocoma (Steud.) Henrard ex Nakai & 수강아지풀 & NIBRVP 0000550310 & \\
\hline Spodiopogon sibiricus Trin. & 큰기름새 & NIBRVP 0000550447 & \\
\hline Stipa pekinensis Hance & 나래새 & NIBRVP 0000550448 & \\
\hline Trisetum bifidum (Thunb.) Ohwi & 잠자리피 & NIBRVP 0000535841 & \\
\hline \multicolumn{4}{|l|}{ Liliaceae 백합과 } \\
\hline Allium macrostemon Bunge & 산달래 & NIBRVP 0000535855 & \\
\hline Allium thunbergii G. Don & 산부추 & NIBRVP 0000550450 & \\
\hline
\end{tabular}


Appendix 1. Continued:

\begin{tabular}{|c|c|c|c|}
\hline Taxon & Korean name & $\begin{array}{l}\text { Voucher } \\
\text { Number }\end{array}$ & $\begin{array}{l}\text { Export } \\
\text { regulation }\end{array}$ \\
\hline Convallaria keiskei Miq. & 은방울꽃 & NIBRVP 0000550411 & $\mathrm{O}$ \\
\hline Disporum smilacinum A. Gray & 애기나리 & NIBRVP 0000550508 & \\
\hline Disporum uniflorum Baker & 윤판나물 & NIBRVP 0000535821 & $\mathrm{O}$ \\
\hline Hemerocallis hakuunensis Nakai & 백운산원추리 & NIBRVP 0000603670 & $\mathrm{O}$ \\
\hline Lilium lancifolium Thunb. & 참나리 & NIBRVP 0000550281 & $\mathrm{O}$ \\
\hline Lilium tsingtauense Gilg & 하늘 말나리 & NIBRVP 0000550369 & $\mathrm{O}$ \\
\hline Polygonatum inflatum Kom. & 퉁둥굴레 & NIBRVP 0000580644 & \\
\hline Polygonatum involucratum (Franch. \& Sav.) Maxim. & 용둥굴레 & NIBRVP 0000550348 & \\
\hline Polygonatum odoratum var. pluriflorum (Miq.) Ohwi & 둥굴레 & NIBRVP 0000535641 & $\mathrm{O}$ \\
\hline Scilla scilloides (Lindl.) Druce & 무릇 & NIBRVP 0000550322 & \\
\hline Smilacina japonica A. Gray & 풀솜대 & NIBRVP 0000535770 & $\mathrm{O}$ \\
\hline \multicolumn{4}{|l|}{ Amaryllidaceae 수선화과 } \\
\hline Lycoris flavescens M. Y. Kim \& S. T. Lee & 붉노랑상사화 (Cultivated) & NIBRVP 0000550293 & $\mathrm{O}$ \\
\hline \multicolumn{4}{|l|}{ Iridaceae 붓꽃과 } \\
\hline Iris minutoaurea Makino & 금붓꽃 & NIBRVP 0000580577 & $\mathrm{O}$ \\
\hline Iris rossii Baker & 각시붓꽃 & NIBRVP 0000580600 & $\mathrm{O}$ \\
\hline \multicolumn{4}{|l|}{ Smilacaceae 청미래덩굴과 } \\
\hline Smilax china $\mathrm{L}$. & 청미래덩굴 & NIBRVP 0000535845 & \\
\hline Smilax nipponica Miq. & 선밀나물 & NIBRVP 0000535819 & \\
\hline Smilax riparia A. DC. & 밀나물 & NIBRVP 0000550396 & \\
\hline Smilax sieboldii Miq. & 청가시덩굴 & NIBRVP 0000535843 & \\
\hline \multicolumn{4}{|l|}{ Dioscoreaceae 마과 } \\
\hline Dioscorea oppositifolia $\mathrm{L}$. & 마 & NIBRVP 0000550300 & \\
\hline Dioscorea quinqueloba Thunb. & 단풍마 & NIBRVP 0000550451 & \\
\hline \multicolumn{4}{|l|}{ Orchidaceae 난초과 } \\
\hline Spiranthes sinensis (Pers.) Ames & 타래난초 & NIBRVP 0000603673 & \\
\hline
\end{tabular}

